\title{
Exploring How the Newsroom Shapes Chinese Viewers' Perception of Journalism
}

\author{
Yian Lin
}

\author{
University of Southern California \\ *Corresponding author. Email: yianl@usc.edu
}

\begin{abstract}
HBO's political drama, The Newsroom, portrayed an American news station undergoing changes in its working ethics. Its portrayal of politics and journalism has sparked discussions among its viewers, and several research have probed into the influence of The Newsroom. This paper aims to present a proposal of exploring how The Newsroom shapes the attitudes towards American politics and journalism of viewers of this show in China. It is hypothesized that Chinese viewers would have a generally positive attitudes towards the two aforementioned factors based on Cultivation Theory from the field of communication. Structured interview and the word cloud analysis will be used as an analysis of the responses from participants. It is proposed that the results would indicate that while the general views of the audience would be positive, there could also be some respondents who do not hold an entirely positive view with regard to actual American journalism due to the perceived idealism of the show.
\end{abstract}

Keywords: Journalism, The Newsroom, Popular culture, TV series, Media

\section{INTRODUCTION}

TV series have always been one major form of people's entertainment in leisure time. TV series of all kinds can influence the viewers in many ways. According to Cultivation Theory, the frequency of people's viewing of the television could have an impact on how the world in the show is perceived by them [1]. The Newsroom, a political TV show produced by HBO, has elicited a wide range of discussions among those who viewed it [3]. Among the existed research regarding The Newsroom and its influence on the viewers, most of them focused on Western viewers' reviews. The studies show that The Newsroom shaped the viewers' notion of the news media and journalism in some way and that the show can have a real-life impact on education as well [3][4]. The proposed study in this paper aims to focus on the influence of the show on viewers in China, specifically focusing on the potential influences it has on Chinese viewers with regard to their news-viewing habits and their perceived notion of news and journalism industry in America. The proposed study allows the influence of the show and the general opinion towards American journalism to be viewed at a different angle regarding a group of viewers in a different culture. This could serve as a potential way to look at the crosscultural influence of TV series and to add insights onto the Cultivation Theory. The study provides a way to help people understand the cultural influece on the social media to some extent.

\section{THE BRIEF INFORMATION OF THE NEWSROOM}

\subsection{The background and context of The Newsroom}

HBO's The Newsroom, written by Aaron Sorkin, depicts a big news station undergoing changes both in the content it airs and the working morals as a new producing team takes over. The main focus of this new team is to produce news that "really matters" instead of focusing on the "gossip and voyeurism" [5]. A fastpaced TV show depicting journalism and focusing on American political events, this show is popular among English-speaking general audience. In a case-study, Peters analyzed the response from the audience of The Newsroom through the forum section on HBO's official site [3]. Over one thousand participants' responses are collected and analyzed to come up with the main topics of these discussions [3]. Summarizing from these topics, the main conclusions include that The Newsroom prompts its audience to discuss and evaluate news and journalism, with some audience think that the show 
could have a real-world implication and others think that The Newsroom is not objective enough [3]. Other impacts that The Newsroom has on its viewers as reflected by the discussion posts are an increased political discussion, a general negative attitude towards the real-life media, and a certain but not deep level of media literacy [3].

Besides the study by Peters which presents the general public's views towards The Newsroom, another study by Peterlin and Peters points out that TV series like The Newsroom could serve the purpose of education [4]. The authors cite the idea of ethnography that TV series that are set in a certain workplace could present college students a near-realistic experience that would help them to learn [4]. Some of the specific topics of journalism the authors mention that could be taught using The Newsroom are ethics, journalist practice, and diversity [4]. According to this study, The Newsroom could serve as a medium to educate and teach [4].

\subsection{The relevant theory based on The Newsroom}

Building on the Peterlin and Peters (2019) research, one theory that they mentioned in the study is cultivation theory [4]. Put forth by Gerbner (1998), the theory is about that exposure to television would make the viewers think that television portrays real life [1]. The theory also states that those who view television for a longer time per day would have a higher tendency to think the programs as representing the reality [1]. Based on this, we could infer that for those who finished watching the whole three seasons of The Newsroom, they would tend to think that the show portrays the journalism industry and news ethics as the reality in the US. Therefore, they may think that American journalism in reality has a high standard in ethics as reflected in the show and would hold a more positive view towards American journalism.

The Newsroom as a TV show about media and journalism essentially reflects an image of the industry of journalism that is depicted in the form of popular culture. This kind of depiction is worth studying since it is a special way of investigating what type of the connection and attitude general public have with the journalism industry, according to a historical review of image of journalism in culture by Saltzman (2005). No matter the characters in journalism and media industry shown in these programs in popular cultures are fictional or are based on true stories, the audience will still perceive them as very real even though they may have never had direct contact with people working in the industry, and this can be contributed to the fact that their lives are depicted in detail through popular media [6]. This also could be connected to the Cultivation Theory that the audience may perceive the what's depicted on television as realistic. Saltzman (2005) suggests that by studying these portrayals, the media and journalists could gain insights about the general perception of journalism in the public and could make decisions about the possible ways to make adaptations regarding this perception as journalism develops with time [6].

The study about the audience's view of The Newsroom done by Peters (2015) mainly investigated English-speaking viewers [3]. The show's impact could be seen in a more comprehensive and diverse way if we extend the similar study to see how the show and its depiction are perceived by people of a different cultural background. In this study proposal, the author decides that studying audience in China, after observing that one of the lines from the show "A doctor announces her death, not the news" has been quoted for many times on Chinese social media when people response to some reports of fake news. This may suggest that The Newsroom is known to many Chinese audience, and that Chinese audience would use its line to imply the importance of truthiness of the news and displaying some media literacy. Therefore, this paper aims to line out a proposal to investigate Chinese viewers' perception of the show The Newsroom.

\subsection{The related questions included in The Newsroom}

Some of the specific questions to be investigated include: would those viewers who finished the entire three seasons have a more positive attitude towards American journalism as an industry? Would the viewers think twice when they see a piece of news after watching this show? Based on the available short reviews online and the Cultivation Theory, it is predicted that the viewers would have a generally positive attitude about American journalism (although some of them would also think that the show predicted an overly idealistic picture) and would have a higher level of media literacy and independent thinking regarding the news [1].

\section{METHOD}

\subsection{Participants}

In the research by Peters (2015), participants of interest were from the online forum of the show [3]. The participants in this proposed study would be obtained from douban.com, which is a Chinese online community on which the users can rate and review movies, TV series, books, and music. Participants will include the users who finished and rated the entire three seasons of The Newsroom. The show has an average number of 46,000 users who rated "watched" across the three seasons on the website, and the last season has 
over 27,000 ratings [7]. Participants could be reached out by direct message on douban.com.

\subsection{Measures}

To investigate the participants' possible influences from the show, online structured interviews would be conducted using online survey tool such as Qualtrics. Participants will be asked open-ended questions about the show. The list of the sample questions is:

What is your overall attitude regarding this show? Did you enjoy it?

Having watched the entire show, what do you think American journalism is like?

What was the experience with The Newsroom for you? What did you mainly feel when you were watching the show?

What are the main working characteristics about the fictional ACN and its team that you observed?

For you, what does an "ideal" or "perfect" news media should be like? What makes a good news outlet?

Has this show changed your habits of viewing and perceiving the news somehow? In what ways?

After all participants completed the interview, their responses will be entered into DICTION, a software for word-cloud analysis. From the word-cloud analysis, we would be able to see the dominating theme of these responses. The demographic information, such as age, gender, and highest level of education of the participants will also be collected in the process of the interview via Qualtrics and will be counted in the final analysis.

\subsection{Predicted Results}

For the possible results of this current proposed study, the author predicts that the overall response of the interviewees will be positive regarding the questions about journalism and news media in the US: based on the existing short comments of users on the main page of The Newsroom on douban.com, it can be seen that some of the reviews indicate a positive tone include "there is much to learn from American journalism" "All journalism students should take a look at this" [7]. On the page of the first season, one most-liked comment state that "the fourth estate is one of the things that make America a great country" [7]. These responses resemble one observation in the article by Peters (2015) that some viewers think The Newsroom could inspire changes in real life [3], and that comments of these kinds could be seen as an indication that some of the viewers perceive the show as a representation of American journalism that has something to be learned from, which corresponds to the Cultivation Theory [1]. Based on this, it could also be inferred that these viewers" notions of "ideal" news that is related to what is portrayed the show. Possible results regarding the question about "ideal" news in the word cloud analysis could be "freedom of speech", "objectivity", and "truth". However, the responses regarding perception of American journalism may also not be entirely positive, since many users also point out in their short comments that The Newsroom is too "idealistic" [7]. "Idealistic" may be one of the main words that is of high frequency in the DICTION results. This may suggest that some participants would not think the show represents the reality to a great extent and tend not to have a highly positive view about American journalism in reality if they think that the show is overly positive in its portrayal of the industry, and they may have a sense that there is a difference between the show and the reality. With this being said, in the reviews of the final season, many viewers states that even though the idealism, they are still moved by the devotion of the main characters and the excitement of the story and they have a generally optimistic view, as one comment in the season one page says that "although the world of journalism in the show my not be entirely objective, it shows the possibility that the news media will speak up and present the truth to the public" [7]. This motivation that some of the viewers perceived may influenced their overall perception of the journalism world of The Newsroom and possibly of America to be more positive. As for the possible changes in viewers' habits regarding viewing the news, there could be respondents stating that they would be more critical in absorbing news information given that the characters in The Newsroom constantly stress the importance of validating the news sources and how crucial it is to produce news that are credible, and also one of the main topics of the second season is about a mistake that the news station and the characters made regarding the credibility of the news they broadcast [5]. This notion may be cultivated in the viewers' perception.

\section{CONCLUSION}

This article discusses a proposed study about the possible influences of The Newsroom on Chinese viewers. Based on existing research, relevant theories, and data from online discussion platforms, it is proposed that the viewers who completed the whole series would tend to have a more positive views towards American journalism, based on Cultivation Theory [1], and that the viewers would think more independently with regard to the news they are exposed to. The proposed method of this study is interviews and a wordcloud analysis of the answers to obtain an overall trend in viewers' attitudes. The author predicts that while a number of viewers will have a positive view towards the show and journalism in America and have the critical thinking towards news and information, the response would not be entirely positive, since some of the 
existing reviews state that this show is too realistic to be true. As well as, the results show the cultrual influence on the social media which may help people to understand it clearly. One possible limitation of the proposed study is that since the word-cloud analysis could only generate findings that are most general, more detailed and precise responses could be omitted. Another possible limitation is that the participants, who are selected from an online platform, would not be representative of all the Chinese viewers of the show. What's more, the validity of the questions may not be very strong. Methods such as structured and valid questionnaires and a more randomized sample could be the improvements of the study. An additional potential topic to be researched is whether there is a relationship between participants' occupation or field of expertise is related to their attitudes toward the show. Using the notion of "decoupling", in the report by Koliska and Eckert (2014), American journalists in general showed negative attitudes toward The Newsroom since they perceive the ideal images, especially the practices of journalism and the way of making the news in the show, clashe with the reality in their job setting, therefore they tend to show more criticism regarding their image [2]. It would be insightful to study journalists' attitudes toward The Newsroom in a different culture to see if the different journalism practices influenced by various culture contexts would shape their views differently.

\section{REFERENCES}

[1] Gerbner, G., Gross, L., Morgan, M., \& Signorielli, N. (1986). Living with television: The dynamics of the cultivation process. Perspectives on media effects, 1986, 17-40.

[2] Koliska, M., \& Eckert, S. (2015). Lost in a house of mirrors: Journalists come to terms with myth and reality in The Newsroom. Journalism, 16(6), 750-767.

https://doi.org/10.1177/1464884914537778

[3] Peters, C. (2015). Evaluating journalism through popular culture: HBO's The Newsroom and public reflections on the state of the news media. Media, culture \& society, 37(4), 602-619.

[4] Peterlin, L. J., \& Peters, J. (2019). Teaching journalism ethics through "the newsroom": an enhanced learning experience. Journalism \& Mass Communication Educator, 74(1), 44-59.

5] Poul, A., Rudin, S., Sorkin, A. (Executive Producers). (2012-2014). The Newsroom [TV series]. HBO Entertainment.

[6] Saltzman, J. (2005). Analyzing the images of the journalist in popular culture: A unique method of studying the public's perception of its journalists and the news media. Association for Education in Journalism \& Communication.

[7] 豆瓣. (n.d.). Retrieved September 23, 2021, from https://www.douban.com/. 